\title{
EFEITO DO CONDICIONAMENTO OSMÓTICO NA GERMINAÇÃO E VIGOR DE SEMENTES DE SORGO COM DIFERENTES QUALIDADES FISIOLÓGICAS ${ }^{1}$
}

\author{
ALEXANDRE BOSCO DE OLIVEIRA², ENÉAS GOMES-FILHO ${ }^{3}$
}

\begin{abstract}
RESUMO - O objetivo nesta pesquisa foi avaliar o efeito do condicionamento osmótico na germinação e no vigor de sementes de sorgo, cultivar IPA 1011, com diferentes qualidades fisiológicas. O delineamento experimental foi o inteiramente casualizado com quatro repetições, no esquema fatorial $2 \times 2$, constando de quatro tratamentos: 1 . sementes envelhecidas; 2 . sementes não envelhecidas; 3. sementes envelhecidas e condicionadas osmoticamente e 4. sementes não envelhecidas e condicionadas osmoticamente. A qualidade das sementes foi avaliada por meio do teor de água (TA), massa de mil sementes (MMS), primeira contagem (PCG), teste de germinação (TG), índice de velocidade (IVG) e tempo médio de germinação (TMG), envelhecimento acelerado (TEA), teste de frio (TF), condutividade elétrica (TCE) e lixiviação de potássio (TLK). Os resultados mostraram que o envelhecimento artificial afeta negativamente o desempenho das sementes de sorgo, podendo tais efeitos serem parcialmente revertidos pelo condicionamento osmótico, sendo que essa técnica não influencia a germinação, mas promove benefícios no vigor das sementes de qualidade fisiológica superior e inferior.
\end{abstract}

Termos para indexação: Sorghum bicolor, condicionamento osmótico, potencial germinativo.

\author{
EFFECTS OF OSMOCONDITIONING ON THE GERMINATION AND VIGOR \\ OF SORGHUM SEEDS WITH DIFFERENT PHYSIOLOGICAL QUALITIES
}

\begin{abstract}
The objective of this study was to evaluate the effect of osmotic conditioning on the germination and vigor of sorghum seeds with different physiological qualities from the IPA 1011 cultivar. The experimental design was completely randomized with four replications in a factorial $2 \times 2$, consisting of four treatments: 1 . aged seeds, 2 . seed not aged, 3 . seeds aged and conditioned osmotically and 4 . seeds not aged and conditioned osmotically. The seeds quality was evaluated from the water content (WC), mass of thousand seeds (MTS), the first germination count (FGC) standart germination test (SGT), germination speed index (GSI), germination mean time (GMT), accelerated aging test (AAT), cold test (CT), electrical conductivity test (ECT) and leaching of potassium test (LPT). The results showed that artificial aging negatively affects the performance of sorghum seeds and such effects can be partially reversed by priming. This technique does not influence germination but further benefits vigor in physiologically superior and inferior seeds.
\end{abstract}

Index terms: Sorghum bicolor, osmotic conditioning, germination potential.

${ }^{1}$ Submetido em 27/07/2009. Aceito para publicação em 23/03/2010. Parte
da Tese de Doutorado apresentada pelo primeiro autor à UFC, Programa de
Pós-Graduação em Agronomia/Fitotecnia, Fortaleza (CE).

${ }^{2}$ Eng. Ag., Prof. Dr. Depto. de Fitotecnia, CCA/UESPI, Rua Almir Benvindo, s/n, Malvinas, 64860-000, Urucuí-PI e-mail: aleufc@gmail.com
${ }^{3}$ Eng. Químico, Prof. Dr., Depto de Bioquímica e Biologia Molecular, CC/ UFC, Caixa Postal 6039, 60455-970, Fortaleza-CE, egomesf@ufc.br, autor para correspondência. 


\section{INTRODUÇÃO}

O sorgo granífero constitui-se atualmente numa importante alternativa para a alimentação animal em nosso país, especialmente em regiões de baixa disponibilidade de água, por apresentar plantas com elevada produção de grãos e com relativa tolerância à seca e a temperaturas elevadas. Além disso, as novas cultivares disponíveis no mercado têm alta produtividade, resistência às doenças e boa estabilidade de produção, diminuindo riscos de perdas para o produtor (Mariguele e Silva, 2002). Entretanto, dentre os fatores limitantes, pode-se destacar a dificuldade de se obter sementes com elevada qualidade física, fisiológica, genética e sanitária capazes de proporcionar o estabelecimento adequado de lavouras com populações de plantas uniformes e vigorosas (Carvalho et al., 2000).

O uso de tratamentos pré-semeadura vem sendo estudado como alternativa para proporcionar maior germinação das sementes e emergência de plântulas mais rápida e uniforme no campo. Dentre os tratamentos utilizados, destaca-se o priming ou condicionamento osmótico, técnica proposta inicialmente por Heydecker et al. (1975), que envolve o controle da hidratação das sementes, em tempo suficiente para permitir que os processos preparatórios essenciais à germinação ocorram sem que haja protrusão da radícula. Em seguida, as sementes podem ser desidratadas.

O condicionamento osmótico permite o desdobramento de reservas e a síntese de metabólitos necessários à germinação, fazendo com que ocorra uma germinação mais rápida das sementes, diminuindo o seu tempo de exposição às condições desfavoráveis, tais como ataques por microrganismos e deficiência hídrica, dentre outras (Marcos Filho, 2005). Apesar dessa técnica ter sido proposta inicialmente para sementes de hortaliças, trabalhos recentes têm mostrado efeitos benéficos desse tratamento na germinação de sementes e no desenvolvimento inicial de plântulas de outras importantes culturas sob condições ideais ou adversas, conforme observado por Murungu et al. (2005) em milho e algodão, Oliveira et al. (2007) em milho doce e Patanè et al. (2009) em sorgo.

A qualidade fisiológica do lote de sementes é um dos fatores que pode influenciar significativamente nos efeitos do condicionamento osmótico. Segundo Carvalho et al. (2000), a germinação de sementes de sorgo não apresenta resposta significativa ao uso do condicionamento osmótico com polietilenoglicol(PEG-6000), quandoas sementes apresentam alto padrão de qualidade fisiológica. Entretanto, estes autores observaram um aumento de 7 pontos percentuais na germinação de sementes envelhecidas artificialmente (42 ${ }^{\circ} \mathrm{C}$ por $96 \mathrm{~h}$ ) após o condicionamento osmótico. Essa técnica, realizada com PEG e água do mar, também permitiu um aumento da germinação de sementes de aspargo com baixa qualidade fisiológica (Bittencourt et al.,2005). Resultados semelhantes a esses foram obtidos por Nascimento e Aragão (2004) e Pereira et al. (2008) em sementes de melão e cenoura, respectivamente. Essas informações evidenciam um possível efeito favorável do condicionamento osmótico em sementes com qualidade fisiológica inferior. Por outro lado, Medeiros Filho et al. (2000), avaliando o vigor de sementes de sorgo osmocondicionadas submetidas ou não ao envelhecimento artificial, constataram através do teste de tetrazólio (Krzyzanowski et al., 1991) que em sementes de qualidade superior o priming em PEG-6000 foi mais eficiente do que a imersão apenas em água.

O trabalho foi desenvolvido com o objetivo de avaliar os efeitos do condicionamento osmótico na germinação e vigor de sementes de sorgo granífero, cultivar IPA 1011, com diferentes qualidades fisiológicas.

\section{MATERIAL E MÉTODOS}

O experimento foi conduzido no período de março a abril de 2009, nos Laboratórios de Análise de Sementes e de Fisiologia Vegetal pertencentes, respectivamente, aos Departamentos de Fitotecnia e de Bioquímica e Biologia Molecular da Universidade Federal do Ceará (UFC), em Fortaleza, CE. Foram utilizadas sementes de sorgo granífero [Sorghum bicolor (L) Moench], cultivar IPA 1011, safra 2008, cedidas pela Empresa Pernambucana de Pesquisa Agropecuária (IPA), em Recife, PE, e armazenadas em frascos de vidro contendo sílica gel, à temperatura de $8^{\circ} \mathrm{C}$.

Para aplicação dos tratamentos, o lote inicial de sementes foi dividido em dois sublotes: em um deles, as sementes foram submetidas ao envelhecimento acelerado de acordo com metodologia descrita por Miranda et al. (2001) para sementes de sorgo, utilizando gerbox adaptado em incubadora BOD a $43{ }^{\circ} \mathrm{C}$, sob umidade relativa do ar próxima de $100 \%$, por 72 horas; o outro sublote de sementes permaneceu sem tratamento (sementes não envelhecidas) e foi utilizado como controle. Após esse procedimento, a metade das sementes de cada um desses sublotes foi submetida ao tratamento de condicionamento osmótico.

Para o condicionamento osmótico das sementes foi empregada a metodologia descrita por Foti et al., 2002 e Patanè et al., 2009, para sementes de sorgo. Para tanto, as sementes foram colocadas em béqueres de $400 \mathrm{~mL}$ 
contendo $200 \mathrm{~mL}$ de solução de PEG-6000 a $250 \mathrm{~g} \mathrm{~L}^{-1}$ a qual, segundo Michel e Kaufmann (1973), corresponde a um potencial osmótico de $-0,86 \mathrm{MPa}$ a $15^{\circ} \mathrm{C}$, onde permaneceram por 48 horas. Para a definição deste tempo de condicionamento, foram feitas curvas de absorção de água das sementes envelhecidas e não envelhecidas. Para isso, quatro subamostras de 50 sementes de cada sublote foram postas sobre duas folhas de papel de filtro mata-borrão saturadas com água destilada e colocadas no interior de caixas gerbox $(11 \times 11 \times 3,5 \mathrm{~cm})$ transparentes, com tampas, as quais foram mantidas em câmara de germinação, sob escuro contínuo e temperatura de 15 ${ }^{\circ} \mathrm{C}$, durante 48 horas. A absorção de água $(A b A)$ pelas sementes foi medida nos tempos de embebição de 0,2 , $4,6,8,10,12,18,24,30,36,42$ e 48 horas. Ao final de cada tempo, as sementes eram retiradas, enxugadas com papel toalha e pesadas, para obtenção do peso úmido. A $A b A$, em percentagem, foi calculada empregando-se a fórmula $A b A=\left(\frac{P_{f}-P_{i}}{P_{i}}\right) \times 100$, onde, $\mathrm{P}_{f}$ representa o peso final das sementes a cada tempo e $\mathrm{P}_{i}$ o peso inicial das sementes antes da embebição.

O condicionamento osmótico foi conduzido em uma incubadora, sob escuro contínuo e aeração constante, a fim de garantir condições normais de respiração das sementes (Bujalski e Nienow, 1991). Na parte inferior de cada béquer foi fixada uma mangueira estreita, com pedra porosa anexada na ponta, a qual se manteve conectada a uma pequena bomba de aquário, responsável pela insuflação de ar na solução. Após o condicionamento, as sementes foram cuidadosamente lavadas e, em seguida, secas com papel de filtro mata-borrão, por 72 horas, em ambiente de laboratório, à temperatura de $25 \pm 2{ }^{\circ} \mathrm{C}$. As sementes foram desinfetadas em solução de hipoclorito de sódio a $1 \%$, por cinco minutos e utilizadas nos experimentos.

As sementes de cada tratamento foram avaliadas por meio dos seguintes parâmetros ou testes:

Teor de água (TA) - foi determinado com base na massa úmida, segundo metodologia descrita por Brasil (1992), utilizando-se quatro subamostras de cinco gramas de sementes para cada tratamento.

Massa de mil sementes (MMS) - foram utilizadas oito subamostras de cem sementes para cada tratamento, a partir das quais se estimou a massa de mil sementes, conforme recomendado por Brasil (1992).

Primeira contagem de germinação (PCG) - foi determinada juntamente com o teste de germinação, registrando-se a porcentagem de plântulas normais no quarto dia após a instalação do ensaio, conforme as Regras de Análises de Sementes (Brasil, 1992).

Teste de germinação (TG) - utilizaram-se 200 sementes por tratamento, em quatro repetições de 50 sementes distribuídas em rolos de papel umedecido com quantidade de água equivalente a 2,5 vezes o peso do substrato seco. A avaliação foi realizada no décimo dia após a semeadura, considerando-se germinadas as sementes que emitiram raiz primária. Os resultados foram expressos em porcentagem média com base no número de plântulas normais (Brasil, 1992).

Índice de velocidade de germinação (IVG) calculado pelo somatório do número de sementes germinadas a cada dia, dividido pelo número de dias decorridos entre a semeadura e a germinação, de acordo com a fórmula definida por Maguire (1962).

Tempo médio de germinação (TMG) - obtido através de contagens diárias das sementes germinadas até o décimo dia após a semeadura e calculado através de fórmula proposta por Labouriau (1983), sendo os resultados expressos em dias.

Teste de envelhecimento acelerado (TEA) utilizaram-se 200 sementes por sublote, em quatro repetições de 50 sementes, distribuídas numa camada única e uniforme, sobre tela de alumínio fixada em caixa de plástico (gerbox), contendo no fundo $40 \mathrm{~mL}$ de água destilada. As caixas plásticas foram mantidas a 43 ${ }^{\circ} \mathrm{C}$, durante 72 horas (Miranda et al., 2001). Após esse período, foi instalado o teste de germinação e a avaliação foi realizada quatro dias após a semeadura, computandose a percentagem de plântulas normais (Brasil, 1992).

Teste de frio (TF) - foi conduzido utilizandose rolo de papel, sem solo, conforme recomendações de Cícero e Vieira (1994), em que quatro repetições de 50 sementes foram distribuídas em rolos de papel umedecido com quantidade de água equivalente a 2,5 vezes o peso do substrato seco. Após a semeadura, os rolos foram colocados no interior de sacos plásticos e vedados com fita adesiva, sendo mantidos em câmara regulada a $10^{\circ} \mathrm{C}$, durante sete dias. Após este período, os rolos foram retirados dos sacos plásticos e transferidos para um germinador à temperatura constante de $25{ }^{\circ} \mathrm{C}$, onde permaneceram por quatro dias, quando então foi calculada a porcentagem de plântulas normais.

Teste de condutividade elétrica (TCE) - quatro repetições de 50 sementes, para cada lote, foram pesadas e colocadas para embeber em copos plásticos 
(capacidade de $200 \mathrm{~mL}$ ) contendo água destilada e mantidas em germinador durante 24 horas à temperatura constante de $25{ }^{\circ} \mathrm{C}$ (Vieira e Krzyzanowski, 1999). A leitura da condutividade elétrica da solução foi realizada em condutivímetro da Marca Analyser, modelo 650, sendo os resultados expressos em $\mu \mathrm{S} \mathrm{cm}^{-1} \mathrm{~g}^{-1}$ de sementes.

Teste de lixiviação de potássio (TLK) - utilizouse o mesmo procedimento adotado para o TCE, com exceção do tempo de embebição das sementes, que neste teste foi de 60 minutos. As leituras foram realizadas em fotômetro de chama MicroNal, modelo B463, sendo os resultados expressos em ppm de potássio por grama de semente (Marcos Filho, 2005).

O delineamento experimental adotado foi 0 inteiramente casualizado, com quatro repetições de 50 sementes, em esquema fatorial $2 \times 2$, tendo como tratamentos a combinação de dois sublotes com sementes de diferentes qualidades fisiológicas (envelhecidas e não envelhecidas) e dois sublotes com condicionamento osmótico (envelhecidas e condicionadas e não envelhecidas e condicionadas). A análise de variância e a comparação de médias foram realizadas através do teste F e Tukey, respectivamente, ambos ao nível de 5\% de probabilidade (Banzatto e Kronka, 2006).

\section{RESULTADOS E DISCUSSÃO}

As sementes envelhecidas e não envelhecidas apresentaram curvas de absorção de água semelhantes (Figura 1). A fase de maior velocidade de absorção ocorreu do início até duas horas de embebição, enquanto a fase de menor velocidade de absorção ocorreu entre 24 e 48 horas de embebição. Com base nesta curva, estabeleceu-se o tempo de 48 horas para o tratamento de condicionamento osmótico em presença de PEG6000 , tendo em vista a alta percentagem de absorção de água nesse tempo. A água é necessária para a digestão das reservas e translocação dos produtos metabolizados, sendo estes processos caracterizados por um padrão trifásico da germinação (Bewley e Black, 1994). Nesse experimento, também se observou que as sementes não envelhecidas emergiram a radícula com 30 horas de embebição, enquanto que para as sementes envelhecidas isso só ocorreu com 42 horas após a embebição (Figura 1). Esse comportamento pode estar relacionado com uma redução na divisão e expansão celular em função do envelhecimento das sementes, resultando em uma germinação mais lenta (Sveinsdóttir et al., 2009).

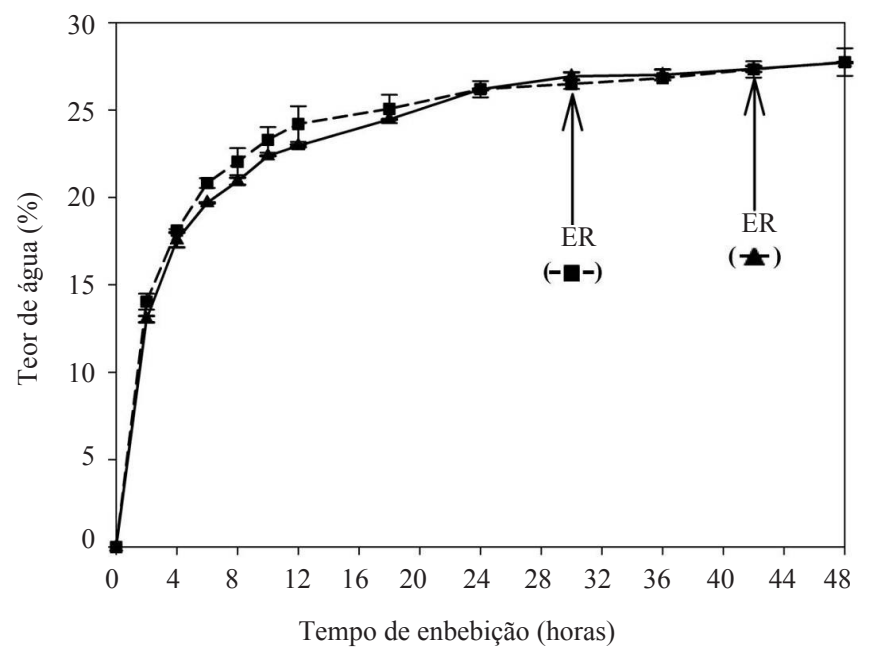

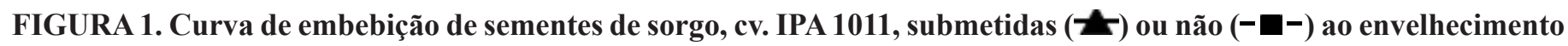
artificial. ER - Emersão da radícula. As barras verticais representam o erro padrão da média.

O TA das sementes aumentou significativamente em função dos procedimentos de envelhecimento artificial e de condicionamento osmótico (Figura 2A). Isto evidencia que em ambos os processos houve aumento na absorção de água pelas sementes, uma vez que aquelas não envelhecidas e não condicionadas (testemunha) apresentaram teor de água inferior aos das sementes dos demais tratamentos. Estes resultados estão de acordo com a afirmação de Marcos Filho (1999) de que, durante o envelhecimento, as sementes são submetidas à condições que favorecem seu umedecimento - alta temperatura e elevada umidade relativa do ar. 


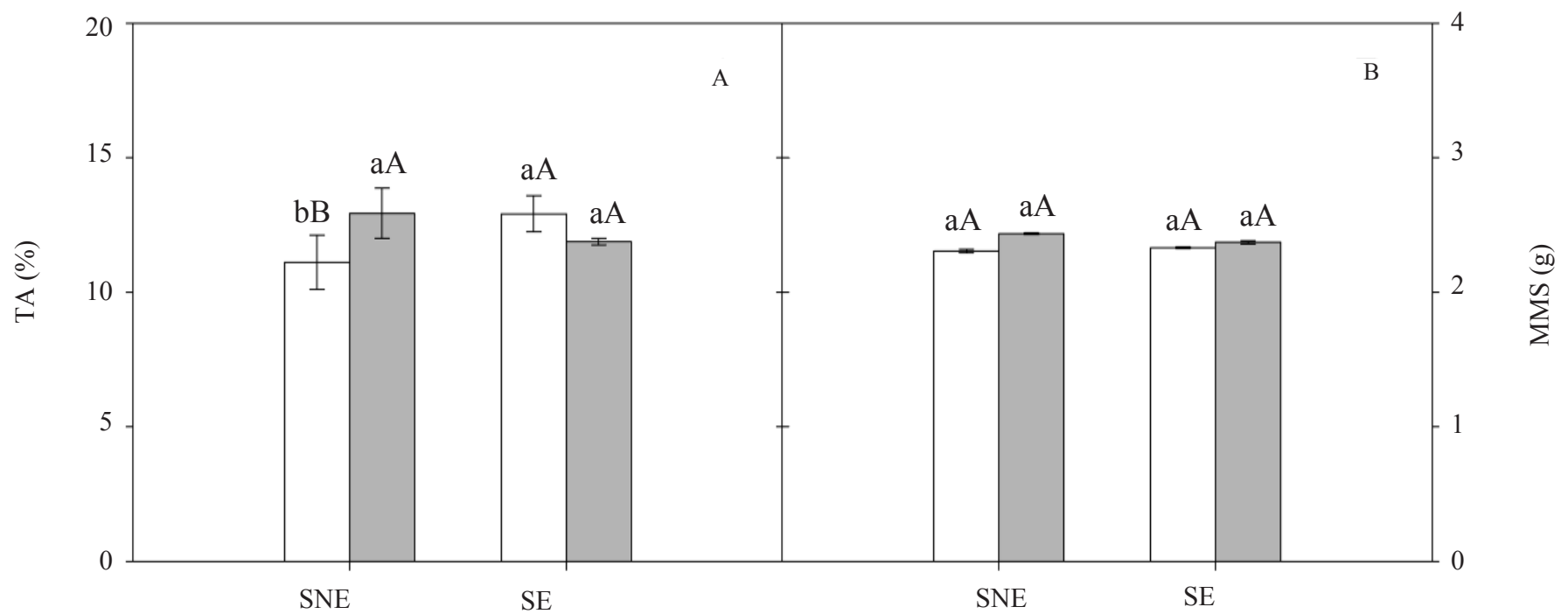

FIGURA 2. Teor de água (TA, A) e massa de mil sementes (MMS, B) de dois sublotes de sementes de sorgo, cv. IPA 1011, não envelhecidas (SNE) e envelhecidas (SE) artificialmente e submetidas ( $\square$ ) ou não ( $\square$ ) ao condicionamento osmótico. Colunas de cores distintas com letras minúsculas iguais, para sementes de mesma qualidade fisiológica, ou colunas de mesma cor com letras maiúsculas iguais, para sementes com diferentes qualidades fisiológicas, não diferem entre si pelo teste de Tukey a 5\% de probabilidade. As barras verticais representam o erro padrão da média.

A MMS de ambos os sublotes de sementes, envelhecidas e não envelhecidas, submetidas ou não ao condicionamento osmótico, foram similares (Figura 2B). Desse modo, apesar das sementes terem absorvido água em quantidades distintas, esta variação não foi suficiente para exercer efeito significativo sobre a variável em questão. A relevância da MMS deve-se a sua utilização para calcular a densidade de semeadura, por ocasião do plantio no campo, bem como, o peso da amostra de trabalho para a análise de pureza em laboratório. Entretanto, os resultados obtidos demonstram que para a cultivar em questão, tais parâmetros não seriam afetados.

Os valores de PCG, TG e IVG foram significativamente reduzidos em função do envelhecimento artificial das sementes, porém não foram afetados pelo condicionamento osmótico das sementes de sorgo (Figuras 3A, 3B e 3C). Para sementes não envelhecidas, o valor médio da PCG foi de $85 \%$, enquanto para aquelas submetidas a esse procedimento foi $59 \%$. A redução nessa variável foi concordante com o maior tempo para emersão da radícula das sementes envelhecidas em relação às não envelhecidas, como observado na Figura 1. Além disso, o IVG das sementes não envelhecidas foi superior àquele das envelhecidas, com valor médio de 7,7 para estas últimas e de 10,8 para as primeiras. A diminuição dos valores deste índice após o envelhecimento natural ou artificial de sementes tem sido atribuída a uma série de alterações metabólicas que ocorrem nas sementes após o envelhecimento acelerado (Sveinsdóttir et al., 2009). Esses resultados demonstram que o envelhecimento artificial foi eficiente para promover a deterioração das sementes, refletida pela menor velocidade de germinação e menores valores de germinação na primeira e na última contagem. Reduções consideráveis nas variáveis em questão também foram observadas por Miranda et al. (2001) em sementes de sorgo submetidas ao envelhecimento acelerado. Quanto ao condicionamento osmótico das sementes de sorgo, Patanè et al. (2009) também constataram que não houve diferença significativa no percentual de germinação de sementes submetidas ou não a esse tratamento. Comportamento semelhante foi observado por Lanteri et al. (1996), Carvalho et al., (2000) e Kikuti et al. (2002) em sementes de pimentão, sorgo e algodão, respectivamente. Esses autores, de forma semelhante ao que foi constatado no presente ensaio, observaram redução significativa na porcentagem de germinação influenciada apenas pela qualidade fisiológica das sementes.

Um dos sintomas mais importantes do declínio da 
qualidade fisiológica das sementes é o aumento do intervalo da germinação da primeira e da última semente, ou seja, a desuniformidade de emergência entre plântulas de um mesmo lote (Oliveira et al., 2009). Assim, a utilização de técnicas que possam acelerar e, conseqüentemente, trazer uniformidade da germinação das sementes, poderá trazer grandes benefícios para os agricultores (Heydecker e Coolbear, 1977). Contudo no experimento em questão não se observou efeito benéfico da técnica do priming sobre a velocidade de germinação das sementes. Resultados similares foram obtidos por Carvalho et al. (2000) em sementes de sorgo, cv. EA-166, submetidas ao condicionamento fisiológico com PEG-6000.

A variável TMG não foi influenciada por nenhum dos fatores avaliados neste experimento, demonstrando que as sementes de sorgo, cv. IPA 1011, se mostraram insensíveis aos processos de envelhecimento artificial e de condicionamento osmótico (Figura 3D). Dessa maneira, observou-se que o condicionamento osmótico não trouxe vantagem quanto à germinação resultado contrário ao observado por Carvalho et al. (2000), que verificaram efeito favorável na germinação de sementes de sorgo de menor potencial germinativo. Por outro lado, os resultados obtidos na presente pesquisa foram semelhantes aos observados por Kikuti et al. (2002), que relataram que o condicionamento osmótico não foi promissor na melhoria da qualidade fisiológica de sementes de algodão. Essas divergências podem estar relacionadas às diferentes metodologias e materiais genéticos utilizados nos experimentos que envolvem a técnica de condicionamento osmótico de sementes, cujo protocolo deve ser estabelecido criteriosamente em função de cada espécie, ou até mesmo, para cada variedade ou cultivar isoladamente.

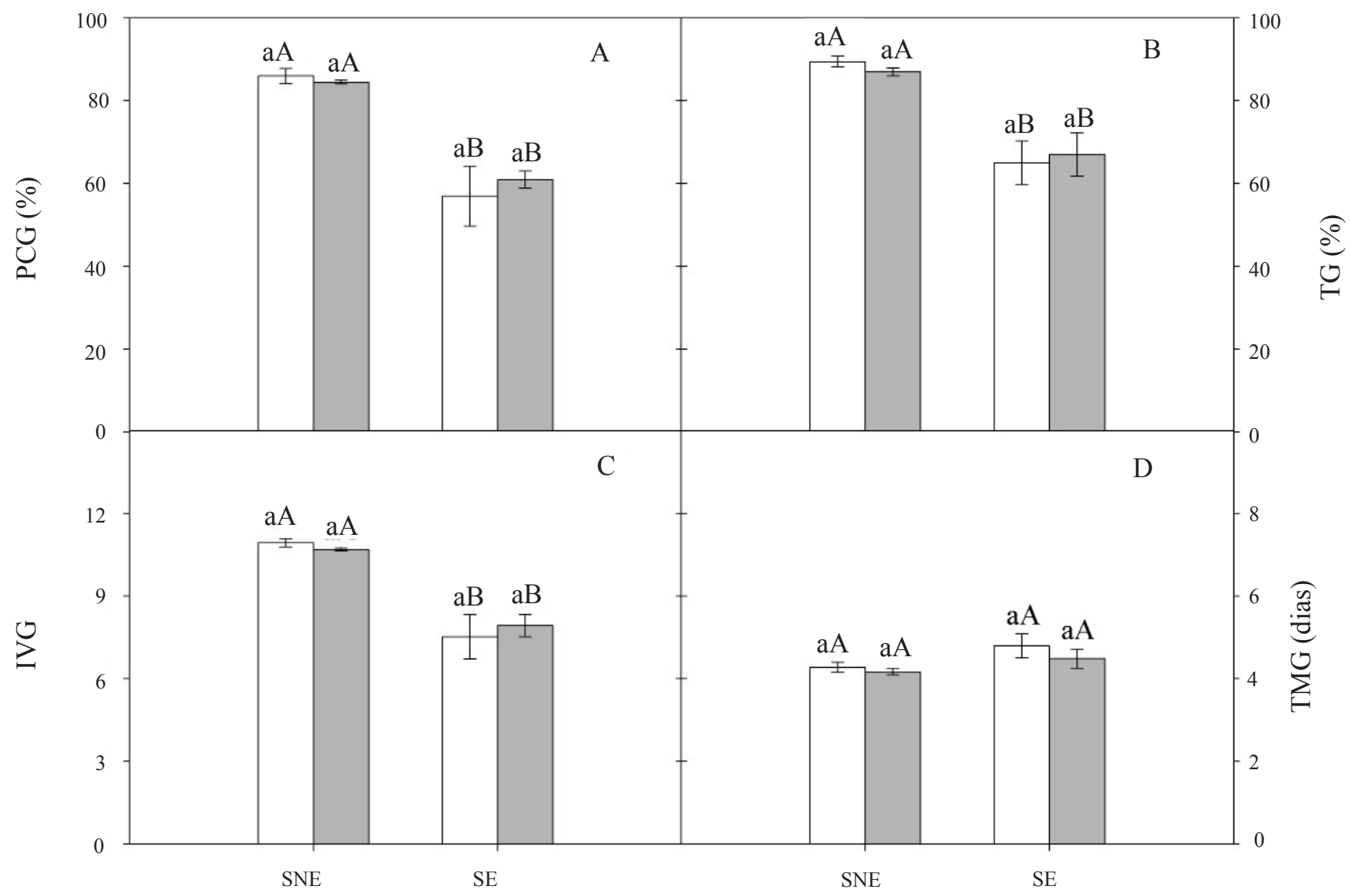

FIGURA 3. Primeira contagem (PCG, A), germinação (TG, B), índice de velocidade (IVG, C) e tempo médio (TMG, D) de germinação de dois sublotes de sementes de sorgo, cv. IPA 1011, não envelhecidas (SNE) e envelhecidas (SE) artificialmente e submetidas $(\square)$ ou não $(\square)$ ao condicionamento osmótico. Colunas de cores distintas com letras minúsculas iguais, para sementes de mesma qualidade fisiológica, ou colunas de mesma cor com letras maiúsculas iguais, para sementes com diferentes qualidades fisiológicas, não diferem entre si pelo teste de Tukey a $5 \%$ de probabilidade. As barras verticais representam o erro padrão da média. 
As sementes com qualidade fisiológica superior (não envelhecidas) apresentaram resposta positiva ao condicionamento osmótico, aumentando o percentual de sementes germinadas no TEA de $45 \%$ para $64 \%$ (Figura 4A). Contudo, o mesmo comportamento não foi verificado para as sementes envelhecidas, as quais não tiveram os valores no TEA influenciados por esse tratamento. Os resultados obtidos, portanto, corroboram com aqueles encontrados por Lanteri et al. (1996), os quais relataram em sua pesquisa que o condicionamento osmótico de sementes não submetidas ao envelhecimento artificial induziu as células embrionárias a entrarem na fase de síntese de DNA e, por conseguinte, aumentarem a taxa de multiplicação celular, o que não foi constatado pelos autores nas sementes de baixo vigor. Concordando com os dados obtidos no presente estudo (Figura 4A), outros trabalhos na literatura têm relatado que, sob condições de alta umidade e alta temperatura proporcionadas pelo TEA, o condicionamento com PEG-6000 proporciona melhor desempenho das sementes em relação à testemunha (Medeiros Filho et al., 2000; Kikuti et al., 2005).

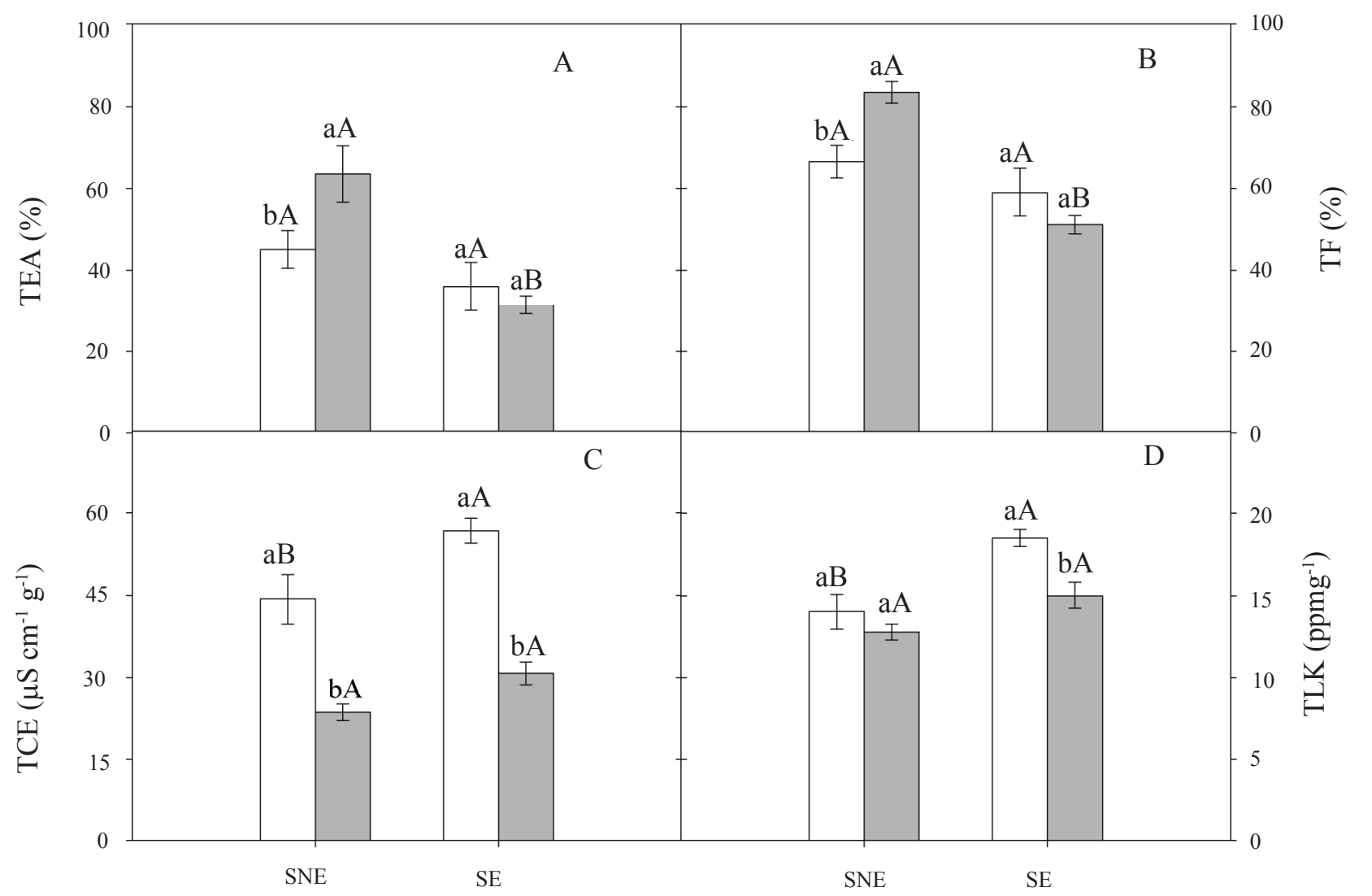

FIGURA 4. Valores médios obtidos nos testes de envelhecimento acelerado (TEA, A), de frio (TF, B), de condutividade elétrica (TCE, C) e de lixiviação de potássio (TLK, D) de dois sublotes de sementes de sorgo, cv. IPA 1011, não envelhecidas (SNE) e envelhecidas (SE) artificialmente e submetidas ( $\square$ ) ou não ( $\square$ ) ao condicionamento osmótico. Colunas de cores distintas com letras minúsculas iguais, para sementes de mesma qualidade fisiológica, ou colunas de mesma cor com letras maiúsculas iguais, para sementes com diferentes qualidades fisiológicas, não diferem entre si pelo teste de Tukey a $5 \%$ de probabilidade. As barras verticais representam o erro padrão da média.

Seguindo o mesmo padrão que se observou para o TEA, o desempenho no teste de frio das sementes de sorgo não envelhecidas foi beneficiado pelo tratamento de priming, com um acréscimo de 17 pontos percentuais em relação à testemunha (Figura 4B). Tais resultados estão de acordo com aqueles obtidos por Kikuti et al. (2005), tendo em 
vista que para o TF tais autores encontraram um aumento de $44 \%$ na porcentagem de plântulas normais oriundas de sementes osmocondicionadas em relação à testemunha. Os resultados aqui obtidos confirmam os benefícios do osmocondicionamento de sementes de boa qualidade fisiológica sobre o percentual e a velocidade de germinação quando estas são semeadas em condições inadequadas de temperatura (Foti et al., 2002; Patanè et al., 2009). Andrade et al. (1994) também salientaram a sensibilidade das sementes de sorgo em relação às condições de estresse como o teste de envelhecimento acelerado e teste de frio. Os resultados aqui obtidos, portanto, demonstram que o vigor das sementes não apresenta resposta significativa ao uso do condicionamento osmótico com PEG-6000 quando estas apresentam baixo padrão de qualidade fisiológica.

O condicionamento osmótico das sementes de sorgo, tanto envelhecidas como não envelhecidas, promoveu redução significativa no nível de material exsudado na solução utilizada para análise no TCE (Figura 4C). O condicionamento osmótico reduziu o valor da condutividade elétrica do exsudado das sementes não envelhecidas de 44,3 para $23,5 \mu \mathrm{S} \mathrm{cm}^{-1} \mathrm{~g}^{-1}$, enquanto nas sementes envelhecidas essa redução foi de 56,8 para $44,3 \mu \mathrm{S} \mathrm{cm}^{-1} \mathrm{~g}^{-1}$. Por esses resultados, infere-se que houve reestruturação do sistema de membranas durante o processo de condicionamento osmótico, impedindo que os solutos fossem lixiviados da semente para a água. Comportamento semelhante foi observado por Kikuti et al. (2002) em sementes osmocondicionadas de algodão.

Miranda et al. (2001), trabalhando com sementes de sorgo, observaram que os testes de vigor aplicados às sementes comparativamente aos testes de germinação, proporcionaram informações mais detalhadas sobre os níveis de qualidade dos diferentes lotes de sementes, principalmente, o TCE. Portanto, destaca-se a importância da utilização conjunta dos resultados de vários testes para a avaliação do potencial fisiológico de sementes, conforme considerou Marcos Filho (1999).

Apesar de ter ocorrido redução da condutividade elétrica da solução de exsudação das sementes osmocondicionadas, independente da qualidade fisiológica destas, os teores de $\mathrm{K}^{+}$nessa solução, durante o TLK, decresceram significativamente apenas nas sementes envelhecidas, os quais diminuíram de 18,5 para $15,0 \mathrm{ppm} \mathrm{g}^{-1}$. Este fato pode estar relacionado com a natureza do material exsudato pela semente de melhor qualidade fisiológica, a qual, certamente, não tinha $\mathrm{o} \mathrm{K}^{+}$como principal elemento lixiviado. Outro aspecto importante a se destacar é que ainda não há na literatura um protocolo específico para avaliação do vigor de sementes de sorgo através do TLK, porém trabalhos anteriores com outras cultivares de sorgo têm mostrado efeitos benéficos do priming sobre as sementes de qualidade fisiológica inferior (Carvalho et al. 2000; Medeiros Filho et al., 2000).

De modo geral, analisando os resultados encontrados neste ensaio, cabe ressaltar a afirmação de Lanteri et al. (1996), de que o condicionamento osmótico de sementes de qualidade fisiológica inferior tem diferentes efeitos na germinação, dependendo do nível de deterioração destas. Heydecker e Coolbear (1977) complementam que lotes de sementes com qualidade fisiológica distintas, respondem diferentemente ao condicionamento osmótico e ressaltam a importância de se relacionar as vantagens do condicionamento osmótico à qualidade fisiológica das sementes.

\section{CONCLUSÕES}

O envelhecimento artificial afeta negativamente o desempenho das sementes de sorgo, podendo tais efeitos serem parcialmente revertidos pela técnica do condicionamento osmótico.

O osmocondicionamento não influencia a germinação, mas promove benefícios no vigor das sementes tanto de qualidade fisiológica superior como inferior.

\section{REFERÊNCIAS}

ANDRADE， R.V.; AZEVEDO, J.T.; BORBA， C.S.; OLIVEIRA, A.C. Teste de vigor em sementes de sorgo para predizer o armazenamento. Revista Brasileira de Sementes, v.16, n.1, p.102-106. 1994.

BANZATTO, D.A.; KRONKA, S.N. Experimentação agrícola. 4.ed. Jaboticabal: UNESP, 2006. 237p.

BEWLEY, J.D.; BLACK, M. Seeds: physiology of development and germination. New York: Plenum Press, 1994. 445p.

BITTENCOURT, M.L.C.; DIAS, D.C.F.S.; DIAS, L.A.S.; ARAÚJO, E.F. Germination and vigour of primed asparagus seeds. Scientia Agricola, v.62, n.4, p.319-324, 2005.

BRASIL. Ministério da Agricultura e Reforma Agrária. Secretaria Nacional de Defesa Agropecuária. Departamento Nacional de Defesa Vegetal. Coordenação de Laboratório Vegetal. Regras para análise de sementes. Brasília, DF, 1992. 365p. 
BUJALSKI, W.; NIENOW, A.W. Large-scale osmotic priming of onion seeds: a comparison of different strategies for oxygenation. Scientia Horticulturae, v.46, n.1/2, p.1324, 1991.

CARVALHO, L.F.; MEDEIROS FILHO, S.; ROSSETTI, A.G.; TEÓFILO, E.M. Condicionamento osmótico em sementes de sorgo. Revista Brasileira de Sementes, v.22, n.1, p.185-192, 2000.

CÍCERO, S.M.; VIEIRA, R.D. Teste de frio. In: VIEIRA, R.D.; CARVALHO, N.M. (Ed.) Testes de vigor em sementes. Jaboticabal: FUNEP, 1994. p.151-164.

FOTI, S.; COSENTINO, S.L.; PATANÈ, C.; D’AGOSTA, G. Effect of osmoconditioning upon seed germination of sorghum (Sorghum bicolor (L.) Moench) under low temperatures. Seed Science and Technology, v.30, n.3, p.521-533, 2002.

HEYDECKER, W.; COOLBEAR, P. Seed treatments for improved performance survey and attempted prognosis. Seed Science and Technology, v.5, n.2, p.353-425, 1977.

HEYDECKER, W.; HIGGINS, J.; TURNER, I.J. Invigoration of seeds? Seed Science and Technology, v.3, n.1, p.881888, 1975.

KIKUTI, A.L.P.; OLIVEIRA, J.A.; MEDEIROS FILHO, S.; FRAGA, A.C. Armazenamento e qualidade fisiológica de sementes de algodão submetidas ao condicionamento osmótico. Ciência e Agrotecnologia, v.26, n.2, p.439-443, 2002.

KIKUTI,A.L.P.;KIKUTI,H.;MINAMI,K.Condicionamento fisiológico em sementes de pimentão. Revista Ciência Agronômica, v.36, n.2, p.243-248, 2005.

KRZYZANOWSKI, F.C.; FRANÇA NETO, J.B.; HENNING, J.B. Relato dos testes de vigor disponíveis para grandes culturas. Informativo ABRATES, v.1, n.2, p.2027, 1991.

LABOURIAU, L.G. A germinação das sementes. Washington: Secretaria Geral da Organização dos Estados Americanos, 1983. 174p.

LANTERI, S.; NADA, E.; BELLETTI, P.; QUAGLIOTTI, L. BINO, R.J. Effects of controlled deterioration and osmoconditioning on germination and nuclear replication in seeds of pepper (Capsicum annum L.). Annals of Botany, v.77, n.6, p.591-597, 1996.
MAGUIRE, J.D. Speed of germination aid in selection and evaluation for seedling emergence and vigor. Crop Science, v.2, n.1, p.176-177, 1962.

MARCOS FILHO, J. Teste de envelhecimento acelerado. In: KRZYZANOWSKI, F.C.; VIEIRA, R.D.; FRANÇA NETO, J.B. (Ed.). Vigor de sementes: conceitos e testes. Londrina: ABRATES, 1999. cap.3, p.1-24.

MARCOS FILHO, J. Fisiologia de sementes de plantas cultivadas. Piracicaba: FEALQ, 2005. 495p.

MARIGUELE, K.H.; SILVA, P.S.M. Avaliação dos rendimentos de grãos e forragem de cultivares de sorgo granífero. Revista Caatinga, v.15, n.1/2, p.13-18, 2002.

MEDEIROS FILHO, S.; CARVALHO, L.F.; TEÓFILO, E.M.; ROSSETTI, E.M. Efeito do condicionamento no vigor de sementes de sorgo. Revista Ciência Agronômica, v.31, n.1/2, p.33-42, 2000.

MICHEL, B.E.; KAUFMANN, M.R. The osmotic potential of polyethylene glycol 6000. Plant Physiology, v.51, n.6, p.914-916, 1973.

MIRANDA, D.M.; NOVEMBRE, A.D.L.C.; CHAMMA, H.M.C.P. Avaliação do potencial fisiológico de sementes de sorgo pelo teste de envelhecimento acelerado. Revista Brasileira de Sementes, v.23, n.1, p.226-231, 2001.

MURUNGU, F.S.; NYAMUGAFATA, P.; CHIDUZA, C.; CLARK, L.J.; WHALLEY, W.R. Effects of seed priming and water potential on germination of cotton (Gossypium hirsutum L.) and maize (Zea mays L.) in laboratory assays. South African Journal of Plant and Soil, v.2, n.1, p.64-70, 2005.

NASCIMENTO, W.M.; ARAGÃO, F.A.S. Muskmelon seed priming in relation to seed vigor. Scientia Agricola, v.61, n.1, p.114-117, 2004.

OLIVEIRA, A.B.; MEDEIROS FILHO, S.; BEZERRA, A.M.E.; BRUNO, R.L.A. Emergência de plântulas de Copernicia hospita Martius em função do tamanho da semente, do substrato e ambiente. Revista Brasileira de Sementes, v.31, n.1, p.281-287, 2009.

OLIVEIRA, A.S.; SILVA-MANN, R.; SANTOS, M.F.; GOIS, I.B.; BARRETTO, M.C.V. Condicionamento osmótico em sementes de milho doce submetidas ao armazenamento. Revista Ciência Agronômica, v.38, n.4, p.444-448, 2007. 
PATANÈ, C.; CAVAllARO, V.; COSENTINO, S.L. Germination and radicle growth in unprimed and primed seeds of sweet sorghum as affected by reduced water potential in $\mathrm{NaCl}$ at different temperatures. Industrial Crops and Products, v.30, n.1, p.1-8, 2009.

PEREIRA, M.D.; DIAS, D.C.F.S.; DIAS, L.A.S.; ARAÚJO, E.F. Germinação e vigor de sementes de cenoura osmocondicionadas em papel umedecido e solução aerada. Revista Brasileira de Sementes, v.30, n.2, p.137-145, 2008.
SVEINSDÓTTIR, H.; YAN, F.; ZHU, Y.; PEITER-VOLK, T.; SCHUBERT, S. Seed ageing-induced inhibition of germination and post-germination root growth is related to lower activity of plasma membrane $\mathrm{H}^{+}$-ATPase in maize roots. Journal of Plant Phisiology, v.166, n.1, p.128-135, 2009.

VIEIRA, R.D.; KRZYZANOWSKI, F.C. Teste de condutividade elétrica. In: KRZYZANOWSKI, F.C.; VIEIRA, R.D.; FRANÇA NETO, J.B. (Ed). Vigor de sementes: conceitos e testes. Londrina: ABRATES. 1999. cap.4. p.1-26. 